\title{
The role of TBP in rDNA transcription by RNA polymerase I in Saccharomyces cerevisiae: TBP is required for upstream activation factor-dependent recruitment of core factor
}

\author{
Joan S. Steffan, Daniel A. Keys, Jonathan A. Dodd, and Masayasu Nomura' \\ Department of Biological Chemistry, University of California, Irvine, California 92697-1700 USA
}

\begin{abstract}
Transcription of Saccharomyces cerevisiae rDNA by RNA polymerase I involves at least two transcription factors characterized previously: upstream activation factor (UAF) consisting of Rrn5p, Rrn9p, Rrn10p, and two more uncharacterized proteins; and core factor (CF) consisting of Rrn6p, Rrn7p, and Rrn11p. UAF interacts directly with an upstream element of the promoter and mediates its stimulatory function, and $\mathrm{CF}$ subsequently joins a stable preinitiation complex. The TATA-binding protein (TBP) has been known to be involved in transcription by all three nuclear RNA polymerases. We found that TBP interacts specifically with both UAF and CF, the interaction with UAF being stronger than that with CF. Using extracts from a TBP (I143N) mutant, it was shown that TBP is required for stimulation of transcription mediated by the upstream element, but not for basal transcription directed by a template without the upstream element. By template competition experiments, it was shown that TBP is required for UAF-dependent recruitment of CF to the rDNA promoter, explaining the TBP requirement for stimulatory activity of the upstream element. We also studied protein-protein interactions and found specific interactions of TBP with Rrn6p and with Rrn9p both in vitro and in the yeast two-hybrid system in vivo. Thus, these two interactions may be involved in the interactions of TBP with CF and UAF, respectively, contributing to the recruitment of CF to the rDNA promoter. Additionally, we observed an interaction between Rrn9p and Rrn7p both in vitro and in the two-hybrid system; thus, this interaction might also contribute to the recruitment of CF.
\end{abstract}

[Key Words: Saccharomyces cerevisiae; TBP; UAF; CF; RNA polymerase I; rDNA promoter]

Received July 15, 1996; revised version accepted August 21, 1996.

In eukaryotes, each of the three nuclear RNA polymerases, RNA polymerase I (Pol I), RNA polymerase II (Pol II), and RNA polymerase III (Pol III), utilizes a different set of basic transcription factors for recognizing and binding to their respective promoters for initiation; polymerases themselves are unable to bind to promoters directly. The TATA-binding protein (TBP) is unique in that it is required for initiation of transcription by all three RNA polymerases (Hernandez 1993). TBP was originally identified as a protein component of TFIID that binds directly to the TATA box present in many Pol II promoters. For these promoters, the function of TBP is well established; TBP, either by itself or as a part of TFIID that also contains other TBP-associated proteins (TAFs), binds directly to the TATA box and recruits first TFIIA and TFIIB, which in turn recruits Pol II together with TFIIF and other basic transcription factors, such as

'Corresponding author.
TFIIE and TFIIH (Conaway and Conaway 1993; Buratowski 1994; Zawel and Reinberg 1995). However, functional roles of TBP in transcription initiation at TATAless Pol II promoters or Pol III promoters are less well understood. Here, in the absence of the TATA box, formation of preinitiation complexes is initiated by specific interactions of promoter elements (e.g., the box A and box B sequences of tRNA promoters) with transcription factor complexes that do not contain TBP (e.g., TFIIIC for tRNA promoters). Subsequently, TBP-TAF complexes (e.g., TFIIIB for tRNA promoters) appear to be recruited mainly through protein-protein interactions. Whether TBP has direct contact with promoter DNA in such instances, and if so, how significant its contribution is to the formation of functionally competent preinitiation complexes, is being actively investigated (e.g., see Struhl 1994; Martinez et al. 1995; Burke and Kadonaga 1996; Joazeiro et al. 1996). In contrast to the above-mentioned Pol II and Pol III systems, the functional role of TBP in the transcription of rDNA by Pol I is least well under- 
stood, even though the requirement of TBP for Pol I transcription has been well established both in mammalian (Comai et al. 1992; Zomerdijk et al. 1994) and yeast (Cormack and Struhl 1992; Schultz et al. 1992) systems.

Factors required for Pol I transcription were initially studied using in vitro systems derived from a variety of metazoan systems (human, mouse, rat, and frog). Two transcription factors, UBF (upstream binding factor) and SL1 (promoter selectivity factor; also called by other names, such as TIF-IB) have been purified and characterized (for review, see Reeder 1992; Paule 1994; Moss and Stefanovsky 1995). SL1 from HeLa cells has been shown to contain TBP in addition to three other polypeptides $\left(\mathrm{TAF}_{\mathrm{I}} 48, \mathrm{TAF}_{\mathrm{I}}\right.$ 63, and $\mathrm{TAF}_{1} 1$ 10) (Comai et al. 1992, 1994; Zomerdijk et al. 1994; see also Eberhard et al. 1993, for TIF-IB purified from mouse cells), but the exact functional role of TBP has remained unclear.

Like rDNA promoters from other systems, the yeast rDNA promoter consists of two elements: a core element and an upstream element (Musters et al. 1989; Kulkens et al. 1991; Choe et al. 1992; Keys et al. 1996). The core element covers $\sim 50$ nucleotides including the transcription start site, extends upstream to $\sim-40$, and is essential for transcription. The upstream element covers a region from $\sim-50$ to $\sim-155$ and is not absolutely required for specific initiation, but is required for a high level of transcription. Regarding transcription factors in the yeast system, we have identified UAF (upstream activation factor) and CF (core factor; called Rrn6/7 complex previously) in addition to the protein encoded by gene RRN3 (Keys et al. 1994, 1996; Yamamoto et al. 1996). CF consists of three proteins, Rrn6p, Rrn7p, and Rrn1lp, encoded by RRN6, RRN7, and RRN11, respectively, and is essential for specific initiation of transcription (Keys et al. 1994; Lalo et al. 1996; Lin et al. 1996). UAF contains three proteins encoded by RRN5, RRN9, and $R R N 10$, respectively, and probably two additional uncharacterized proteins, p30 and p18, and is not absolutely required for specific transcription, but is required for a high level of transcription (Keys et al. 1996). It has been shown that UAF alone interacts with the upstream element of the template, forming a stable UAF-template complex and committing that template to transcription (Keys et al. 1996). In contrast to UAF, CF does not bind stably to the rDNA template by itself but joins a stable preinitiation complex in the presence of some other factors present in crude cell extracts (Keys et al. 1994). Thus, recruitment of CF to the rDNA promoter to form a stable preinitiation complex must require UAF and possibly some additional proteins.

Both mammalian SLl and yeast CF are essential transcription factors, and even though there is no amino acid sequence similarity between the three TAFs in SL1 and the three protein subunits in $\mathrm{CF}$, these two factors might be functionally homologous. However, SL1 contains TBP, whereas purified CF preparations do not. Although weak interactions between CF (and protein subunits in $\mathrm{CF}$ ) and TBP were observed previously (unpublished experiments cited in Keys et al. 1994; Lalo et al. 1996), we wished to study such interactions in a more systematic way to gain information relevant to the functional roles of TBP in this system. In parallel, we also studied the interactions of TBP with UAF. As we describe in this paper, we have observed that TBP interacts with both CF and UAF and, in fact, interacts with UAF more strongly than with CF. Because of this finding, we then asked whether TBP, together with UAF, participates in recruitment of CF to the rDNA promoter to form a stable preinitiation complex. We have found that this is indeed the case and that, in addition to UAF, TBP is also required to mediate the stimulatory function of the upstream element of the yeast rDNA promoter. We also describe protein-protein interactions between TBP and subunits of UAF and CF, which might be important for recruitment of $\mathrm{CF}$ to the rDNA promoter.

\section{Results}

\section{Interaction of TBP with $C F$ and $U A F$}

$\mathrm{CF}$ and UAF were affinity-purified from strain NOY732 expressing HAl-epitope-tagged RRN7 and from strain NOY662 expressing HAl-epitope-tagged $R R N 5$, respectively. They were incubated with GST-TBP fusion protein bound to glutathione-agarose beads under three different buffer-salt conditions. After incubation, the beads were washed with the same buffers used for the incubation, and the hound proteins were eluted specifically with glutathione. The presence of CF or UAF in the eluates was detected by Western immunoblot analysis using anti-HAl antibodies to detect the HAl-tagged protein components $\left[(\mathrm{HA} 1)_{3}-\mathrm{Rrn} 7 \mathrm{p}\right.$ for $\mathrm{CF}$ and $(\mathrm{HA} 1)_{3^{-}}$ Rrn5p for UAF] and by specific in vitro Pol I transcription assay to measure their ability to complement CF- or UAF-deficient mutant extracts. We observed that UAF bound to GST-TBP, but not to control GST or to the glutathione beads, under all three salt conditions, 200 $\mathrm{mm} \mathrm{KCl}, 400 \mathrm{~mm} \mathrm{KCl}$ and $400 \mathrm{~mm} \mathrm{~K}$ glutamate, as assayed by Western immunoblot (data not shown) and by complementation activity (Fig. 1B, lanes 4, 7, and 10). In contrast, binding of CF to GST-TBP was observed only with $400 \mathrm{~mm} \mathrm{~K}$ glutamate (Fig. 1A, lane 10), but not with $200 \mathrm{~mm} \mathrm{KCl}$ or $400 \mathrm{~mm} \mathrm{KCl}$ (Fig. 1A, lanes 4 and 7; data for Western blot analysis not shown). We conclude that both CF and UAF interact specifically with TBP in vitro, but binding of UAF to TBP is apparently stronger than that of CF to TBP in high concentrations of $\mathrm{KCl}$.

\section{In vitro stimulation of $r D N A$ transcription by $T B P$ using promoters with and without the upstream element}

Because of the observed (unexpected) strong interaction of TBP with UAF, we considered the possibility that TBP functions, at least in part, as a complex with UAF in rDNA transcription. As described in the introduction, UAF interacts with the upstream element of the rDNA promoter and helps to recruit CF to the promoter. Using extracts prepared from an rrn10 mutant strain deficient 
A CF complex

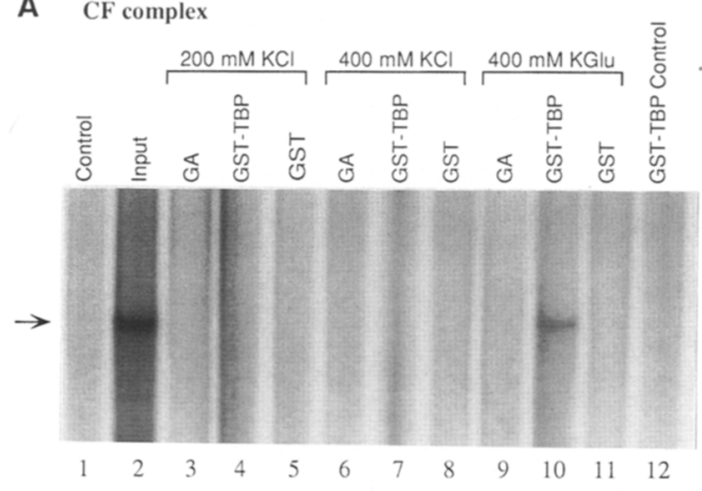

B UAF complex

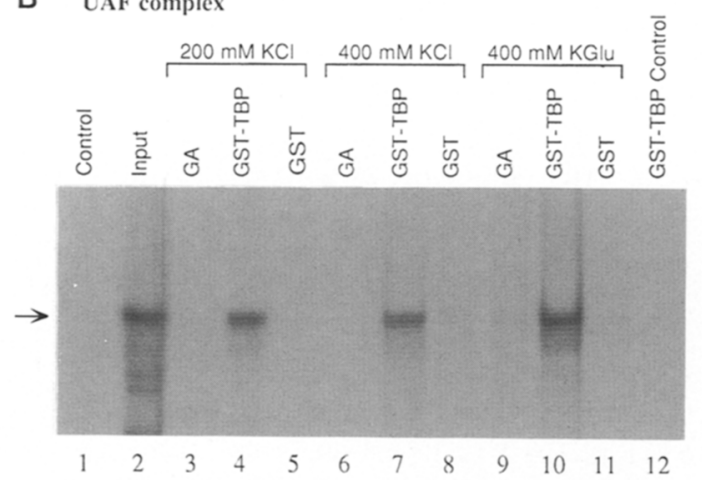

Figure 1. Binding of epitope-tagged $\mathrm{CF}$ and UAF complexes to GST-TBP. (A) Affinity-purified CF [containing (HAl) $)_{3}-\mathrm{Rrn} 7 \mathrm{p}$ ] was applied to glutathione-agarose beads containing bound GST-TBP or GST, or glutathione-agarose (GA) beads alone, as indicated. The beads were equilibrated, loaded, and washed with buffer containing either $200 \mathrm{~mm} \mathrm{KCl}, 400 \mathrm{~mm} \mathrm{KCl}$, or 400 mM K glutamate (KGlu), as indicated. Bound complexes were then specifically eluted with the same buffer-salt solution containing $30 \mathrm{~mm}$ glutathione and eluates were analyzed for the ability to complement a transcription extract lacking CF (a mutant $r r n 6$ extract). The mutant extract was supplemented with 4 $\mu \mathrm{l}$ (of $10 \mu \mathrm{l}$ total, see Materials and Methods) of the indicated eluate per reaction (lanes 3-11). As controls, the mutant extract was supplemented with affinity-purified CF $15 \%$ of the amount that was loaded onto the glutathione-agarose columns, lane 2), or with no addition (lane 1) or supplemented with the eluate from a GST-TBP column (in $400 \mathrm{~mm}$ KGlu buffer) to which no CF was added (lane 12, demonstrating that the complementing activity is not due to the eluted GST-TBP itself). (B) Binding of affinity-purified UAF to GST-TBP (and control) beads was similarly assayed by in vitro transcription reaction using an extract lacking UAF (a mutant rrn10 extract). The mutant extract was supplemented with $4 \mu \mathrm{l}$ (of $10 \mu \mathrm{l}$ total eluate, see Materials and Methods) of the indicated eluate per reaction (lanes 3-11), with affinity-purified UAF ( $5 \%$ of the amount that was loaded onto the glutathione-agarose columns; lane 2), with the eluate from a GST-TBP column (in $400 \mathrm{~mm}$ KGlu buffer) to which no UAF was added (lane 12), or with no addition (lane 1). Transcription was carried out, and radioactive RNA synthesized was analyzed by urea-PAGE. Autoradiograms are shown. Note that, because $40 \%$ of each eluate was assayed, equal intensity of a sample band and an input means approximately $12.5 \%$ recovery of a complex after binding/elution in these experiments. in UAF, it was shown previously that weak basal transcription obtained with an rDNA template missing an intact upstream element does not require UAF nor is it stimulated by UAF; a large stimulation of transcription by UAF takes place only with an rDNA template carrying an intact upstream element (Keys et al. 1996). Similar experiments were carried out using extracts from a temperature-sensitive TBP mutant (spt15; I143N; see Schultz et al. 1992) and effects of addition of purified wild-type recombinant TBP on transcription of rDNA in this system were examined using template with or without the upstream element. Extracts prepared from this mutant were shown previously to be almost completely inactive in promoter-specific initiation for all three polymerases (Schultz et al. 1992).

As shown in Figure 2, the extracts showed a weak but recognizable transcription activity on the rDNA template with or without the upstream element (Fig. 2A, lanes 1 and 5). The addition of purified recombinant TBP to such extracts showed a substantial stimulation (fourfold in Fig. 2A) of transcription for an rDNA template with the upstream element (Fig. 2A, lanes 5-8), but no significant stimulation was observed for an rDNA template without the upstream element (Fig. 2A, lanes 1-4; see the legend for quantitative data). The weak transcrip-

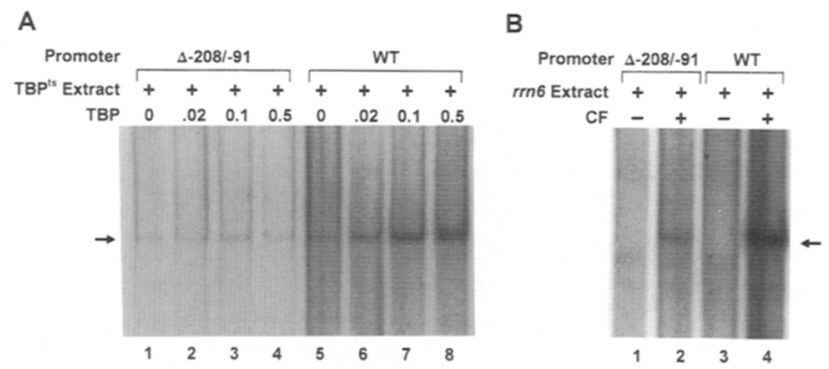

Figure 2. Effects of addition of TBP on rDNA transcription by an extract from a temperature-sensitive TBP (I143N) mutant using template with or without the upstream element. $(A) \mathrm{Pu}$ rified His-tagged TBP $(0,0.02,0.1$, or $0.5 \mu l$; lanes $1-4$, respectively, and lanes $5-8$, respectively) was added to a transcription extract (D-300 + PC-300 fractions) prepared from TBP mutant strain SHY70. (The amount of the mutant TBP present in a reaction mixture was roughly equal to $0.05 \mu$ l of the wild-type TBP as judged by Western immunoblot.) Either DNA template pSIRT $\Delta-208 /-91$ (containing a deletion in the upstream promoter element; lanes 1-4) or pSIRT (containing a wild-type promoter, lanes 5-8) was used. (B) A transcription extract prepared from an rrn6 deletion strain (NOY567) was assayed in the presence of affinity-purified CF complex (lanes 2 and 4) or in its absence (lanes 1 and 3), using either DNA template pSIRT $\Delta$ 208/-91 (lanes 1 and 2) or pSIRT (lanes 3 and 4). Radioactive RNA synthesized was analyzed by urea-PAGE followed by autoradiography. Autoradiograms are shown. The arrow marks the position of the specific Pol I transcript. The results were quantified by densitometry; the relative amounts of specific transcript in $A$, normalized to the amount in lane 1 were 1.0 , $0.8,1.2$, and 0.7 for lanes $1-4$, respectively, and 1.5, 2.5, 6.0, and 5.0 for lanes $5-8$, respectively. Similarly, the values in $B$ were $<0.2,1.0,<0.2$, and 8.3 for lanes $1-4$, respectively, normalized to the amount in lane 2 . 
tion observed with the rDNA template without the upstream element appears to be specific, because the transcript was not observed if extracts were prepared from an rrn6 mutant (Fig. 2B, lane 1), and the addition of $\mathrm{CF}$ allowed (weak) transcription to take place from this mutant promoter (Fig. 2B, lane 2). Transcription from the wild-type template was also completely dependent on the presence of CF and, as expected, was much higher than that from the mutant template (Fig. 2B, cf. lanes 3 and 4 with lane 2). Thus, the results of transcription experiments using a TBP (I143N) mutant extract were similar to those obtained using extracts deficient in UAF (Keys et al. 1996) and were different from those obtained using extracts deficient in CF. Basal transcription from a template with the core element required CF and was not enhanced by TBP or UAF. This suggests that the function of TBP is to mediate the stimulatory activity of the upstream element together with UAF. However, we cannot exclude the possibility that TBP is also required for transcription from the template with the core element only, and that the I143N mutation abolishes TBP's function to mediate the stimulatory activity of the upstream element without affecting the (hypothetical) separate function required for transcription from the core element. We also note that, in the experiment using the TBP mutant extracts as shown in Figure 2A, the wildtype promoter without TBP addition showed a slightly $(\sim 50 \%$ in Fig. $2 \mathrm{~A})$ higher activity compared with the mutant promoter without the upstream element $/ \mathrm{cf}$. lane 5 with lane 1). It is possible that there is a residual activity in the mutant extracts. Alternatively, it may be that TBP is not absolutely required for UAF-dependent recruitment of $\mathrm{CF}$, and that $\mathrm{UAF}$ and other factors in conjunction with the upstream element are able to stimulate, although very inefficiently, recruitment of CF to the promoter in the absence of the intact TBP.

\section{TBP is required for the stable binding of CF to the rDNA template}

It was previously shown that UAF interacts with the upstream element directly, forming a stable complex and committing the template to transcription (Keys et al. 1996). CF subsequently joins the committed complex (Keys et al. 1994), but we have noted previously that factors other than UAF are required for recruitment of CF to form a stable preinitiation complex /data not shown). Thus, the simplest possibility to explain the TBP requirement is that TBP is required for the recruitment of CF to the promoter mediated by the upstream element and UAF. We have examined this possibility directly by carrying out template competition experiments as outlined in Figure 3B. Two rDNA templates with the wild-type promoter, which give specific transcripts with different sizes, were used. Template A was incubated with affinity-purified UAF and /a limited amount of) CF, and with a PC-300 fraction (which does not contain CF nor UAF) prepared from a TBP (I143N) mutant extract together with various amounts of TBP to see whether the CF was stably bound to this tem-

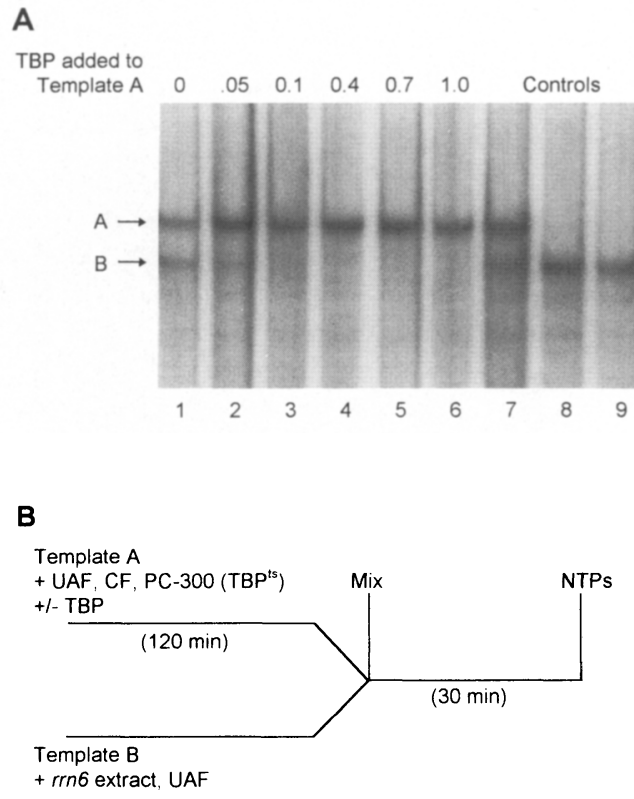

Figure 3. TBP, together with UAF, is required for the stable binding of $\mathrm{CF}$ to the rDNA template. A template commitment experiment was performed to investigate the requirement of TBP for the commitment of CF to the rDNA template as diagrammed in $B$. Template $\mathrm{A}$ (pSIRT) was preincubated with purified UAF, partially purified $C F$, a PC-300 fraction prepared from TBP mutant strain SHY70, and an increasing amount of His-tagged TBP $(0,0.05,0.1,0.4,0.7,1.0 \mu \mathrm{l}$; lanes $1-6$, respectively). Template B (pSIRT $\Delta+39 /+128)$ was separately preincubated with an $r r n 6$ mutant extract (D-300 + PC-300 fractions) supplemented with purified UAF. After incubation for $2 \mathrm{hr}$ at room temperature, the two incubation mixtures were combined and incubated for an additional $30 \mathrm{~min}$, and then the transcription reaction was initiated. As controls, the two template/factor mixtures were added together without preincubation (lane 7); CF was omitted from the template A mixture and was instead preincubated with template B $\mid+$ rrn6 mutant extract; lane 8 ), and UAF was omitted from the template A mixture (and was instead preincubated with the template B mixture so that the total amount in the reaction was constant; lane 9). All the control reaction mixtures contained $1.0 \mu \mathrm{l}$ TBP. Radioactive RNA synthesized was analyzed by urea-PAGE followed by autoradiography. An autoradiogram is shown.

plate under these conditions. [Preliminary experiments showed that incubation of the template with UAF, CF, and TBP alone does not form a stable complex containing CF and that some protein(s) contained in the PC-300 fraction (from a wild-type strain) is required for stable complex formation. Hence, this PC-300 fraction was replaced by a PC-300 fraction from the TBP (I143N) mutant plus purified TBP to examine the role of TBP.] After incubation, this reaction mixture was combined with another reaction mixture containing template $B$ that was preincubated with rrn6 extract supplemented with UAF. The rrn6 extract is deficient in CF, but contains all other proteins required for specific transcription of the rDNA template, including TBP and UAF. Extra UAF was added to insure efficient "capture" of any CF that was not sta- 
bly bound to template A. If CF preincubated with template $\mathrm{A}$ is not stably bound to the template during the preincubation, CF will become available for template $\mathrm{B}$ upon mixing of the two reaction mixtures, and template $B$ will be transcribed upon subsequent addition of nucleoside triphosphates. However, if $\mathrm{CF}$ is stably bound to template A, CF will not be available to template B, and only template A will be transcribed following mixing, addition of nucleoside triphosphates, and incubation. As shown in Figure 3A, without external addition of TBP, both templates A and B were transcribed (lane 1), but preincubation of template $A$ in the presence of increased amounts of TBP allowed the formation of a stable complex containing CF with increased efficiency, thus decreasing the amounts of $\mathrm{CF}$ available to template $\mathrm{B}$ (lanes 2-6).

Three control reactions were carried out. First, the two template/factor reaction mixtures described above were combined without preincubation. As expected, both templates were transcribed, indicating that $\mathrm{CF}$ was available to both templates (Fig. 3A, lane 7). Second, CF was omitted from the template A mixture and was instead preincubated with template B (together with the rrn6 mutant extract and UAF). As can be seen in lane 8, template $B$, but not template $A$, was transcribed, indicating that $C F$ was first stably bound to template $B$ and was excluded from use by template A. Third, UAF was omitted from the template A mixture and the result was exclusive transcription of template B (lane 9), showing that stable binding of $\mathrm{CF}$ to template A requires the presence of UAF. Thus, the results of these template competition experiments show that stable binding of CF to the rDNA template requires both UAF and TBP and that the function of TBP (to recruit CF) revealed in these experiments can account largely, if not exclusively, for the requirement of TBP for rDNA transcription by Pol I in vitro.

\section{Physical interactions of TBP with CF and UAF subunit proteins}

We have reported previously that the three subunit proteins of CF, Rrn6p, Rrn7p, and Rrn1 lp, interact strongly with each other and that Rrn $7 p$ and Rrn $11 p$ individually interact specifically but weakly with TBP (Lalo et al. 1996). This latter conclusion is based on the observations that ${ }^{35} \mathrm{~S}$-labeled TBP was bound to GST-Rrn7p and GST-Rrn1lp fusion proteins affixed to glutathione-agarose beads, but not to control GST-glutathione-agarose beads (Lalo et al. 1996). However, in the previous work we were unable to prepare intact GST-Rrn6p fusion protein, and the possible interaction of TBP with GSTRrn6p was not studied. In the present work, we prepared ${ }^{35}$ S-labeled Rrn6p, Rrn7p (HA1-epitope-tagged), Rrn1lp, and Rrn9p using a reticulocyte in vitro translation system, and their interactions with GST-TBP fusion protein bound to glutathione-agarose beads were studied using buffer-salt conditions similar to those used for the study of interactions of CF and UAF with GST-TBP described earlier in this paper. Interactions with GST bound to glutathione-agarose were used as a control. For technical reasons, we did not study interactions of Rrn5p or Rrn10p with GST-TBP and GST in the same way.

As shown in Figure 4, all three CF subunit proteins, Rrn6p, Rrn7p, and Rrn11p, bound to GST-TBP, but not to GST, in the presence of $200 \mathrm{~mm} \mathrm{~K}$ glutamate or 200 mM KCl (Fig. 4, lanes 2, 3, 7, 8, 12, and 13), but the amounts that were bound to GST-TBP glutathione-agarose beads were higher for Rrn6p than Rrn 1 lp or Rrn7p. Binding of Rrnllp was less, and that of Rrn7p was least (see Table 1). In the presence of $400 \mathrm{~mm} \mathrm{KCl}$, significant binding of ${ }^{35} \mathrm{~S}$-labeled Rrn6p to GST-TBP was still observed (Fig. 4, lane 4), whereas no or only marginally significant binding was observed for ${ }^{35} \mathrm{~S}$-labeled Rrn $11 \mathrm{p}$ or ${ }^{35}$ S-labeled Rrn7p (Fig. 4, lanes 9 and 14; Table 1).

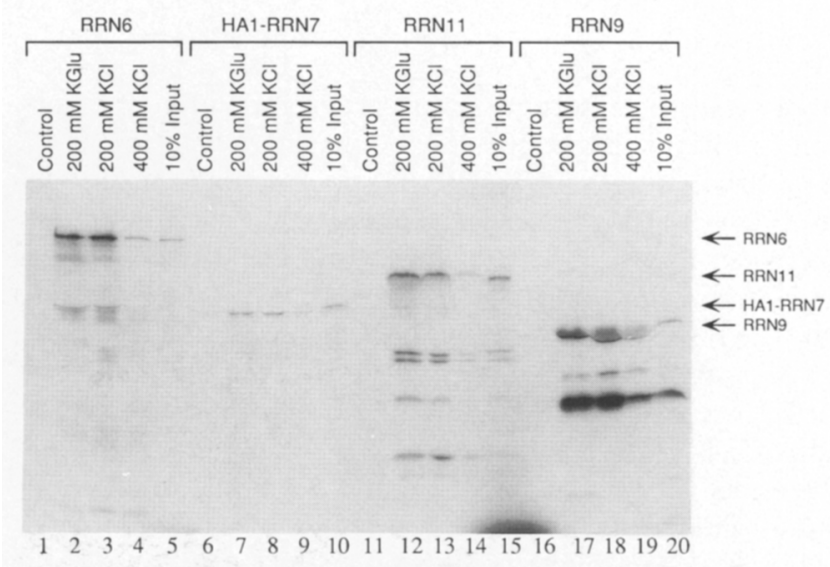

Figure 4. Binding of $\left[{ }^{35} \mathrm{~S}\right]$ methionine-labeled CF subunits (Rrn6p, Rrn7p, and Rrnllp) and a subunit of UAF (Rrn9p) to GST-TBP beads. ${ }^{35}$ S-Labeled Rrn6p (lanes 1-4), HA1-Rrn7p (lanes 6-9), Rrnl lp (lanes 11-14) and Rrn9p (lanes 16-19) were used to study their binding to GST-TBP or GST attached to glutathione-agarose beads. Control GST beads were incubated and washed with buffer containing $200 \mathrm{~mm} \mathrm{~K}$ glutamate (KGlu) for each ${ }^{35} \mathrm{~S}$-labeled probe as shown in lanes $1,6,11$, and 16. GST-TBP beads were incubated and washed for each probe with buffer containing $200 \mathrm{~mm}$ KGlu (lanes 2, 7, 12, and 17), $200 \mathrm{~mm}$ $\mathrm{KCl}$ (lanes 3, 8, 13, and 18) and $400 \mathrm{mM} \mathrm{KCl}$ (lanes 4, 9, 14, and 19). ${ }^{35} \mathrm{~S}$-Labeled proteins bound to the beads were then analyzed by SDS-PAGE; $10 \%$ of each of the input of the labeled proteins was also analyzed (lanes 5, 10, 15, and 20). ${ }^{35}$ S-Labeled Rrn6p and HAl-Rrn7p were added in approximately equal molar ratio, while the amounts of ${ }^{35} \mathrm{~S}-\mathrm{R}$ rnl $1 \mathrm{p}$ and Rrn9p added were about three and two times higher, respectively, relative to these probes (with respect to the intact proteins). An autoradiogram of the gel is shown. The position of each intact labeled protein probe is indicated by an arrow at the far right. It should be noted that the binding conditions used in this experiment are similar to those used for the binding of intact CF (or UAF) to GST-TBP or GST-glutathione-agarose beads shown in Fig. 1, although bound proteins were analyzed directly without specific elution in the experiments shown in this figure, whereas analyses were done on eluates in Fig. 1. Thus, some of the apparently specific interactions observed, for example, those between Rrn6p and TBP in $\mathrm{KCl}$ buffers, appear to be absent when Rrn6p is part of CF. These "masked" interactions might become significant under some other conditions, for example, in KGlu buffers (Fig. 1) or in actual in vivo conditions. 
Table 1. Binding of ${ }^{35}$ S-labeled proteins to GST-TBP and GST in various salt conditions

\begin{tabular}{lccccc}
\hline & \multicolumn{4}{c}{${ }^{35}$ S probes (\% bound) } \\
\cline { 2 - 5 } & Rrn6p & Rrn7p & Rrn1lp & Rrn9p \\
\hline GST, 200 mM KGlu & 1 & 2 & 1 & 2 \\
GST-TBP, 200 mM KGlu & 69 & 11 & 27 & 73 \\
GST-TBP, 200 mM KCl & 60 & 7 & 16 & 61 \\
GST-TBP, 400 mM KCl & 11 & 4 & 5 & 22 \\
\hline
\end{tabular}

Binding/wash conditions include $25 \mathrm{~mm}$ Tris- $\mathrm{HCl}$ at $\mathrm{pH} 8.0$, $30 \%$ glycerol, $0.2 \% \mathrm{BSA}, 0.5 \%$ Tween- 20 , and $\mathrm{KCl}$ or $\mathrm{K}$ glutamate (KGlu) at various concentrations indicated. The amounts of ${ }^{35} \mathrm{~S}$-labeled bands corresponding to intact proteins were analyzed after SDS-PAGE and compared with those used as input. Values given are averages of two experiments, one of which is shown in Fig. 4.

Although the interactions observed for individual subunit proteins might possibly be masked when intact CF is incubated with GST-TBP / see comments in the legend to Fig. 4 for "masking"), it is likely that the interaction between Rrn6p and TBP, which was the strongest interaction detected with a CF subunit, may be responsible for the observed interaction between intact CF and TBP.

Although we have not studied other UAF subunit proteins, we observed a strong interaction between Rrn9p and GST-TBP (Fig. 4, cf. lanes 17-19 with 16 and 20). Here, as much as $22 \%$ of input Rrn9p was retained by GST-TBP beads in the presence of $400 \mathrm{~mm} \mathrm{KCl} \mathrm{(Table} \mathrm{1).}$ Thus, it is possible that the interaction detected between Rrn9p and GST-TBP may be responsible for the observed relatively strong interaction between intact UAF and GST-TBP.

In parallel to the studies on the interactions of CF and UAF subunit proteins with TBP, we also carried out experiments to study direct protein interactions among these subunit proteins. Results of the interactions among CF subunit proteins were reported previously (Lalo et al. 1996). In addition, we discovered an interaction between Rrn9p and GST-Rrn7p fusion protein bound to glutathione-agarose beads (Fig. 5; Table 2). ${ }^{35} \mathrm{~S}$ labeled Rrn9p bound to these beads, but not to control GST-glutathione-agarose beads (cf. lane 2 with lane 1). Control experiments shown in Figure 5 included testing of $a{ }^{35} \mathrm{~S}$-labeled deletion derivative of Rrn9p that is missing about $40 \%$ (amino acid 48-197) of the protein, as well as ${ }^{35}$ S-labeled Rrn6p. Rrn6p bound strongly to GSTRrn7p (lane 8), confirming the previous results (Lalo et al. 1996). The deletion derivative ( $\Delta 48-197)$ of Rrn9p did not show significant binding (lane 5 ), thus serving as a negative control in these binding experiments.

Protein-protein interactions analyzed by the yeast two-hybrid system

The yeast two-hybrid system has been used extensively for detecting protein-protein interactions (Fields and Sternglanz 1994; Phizicky and Fields 1995). We used this

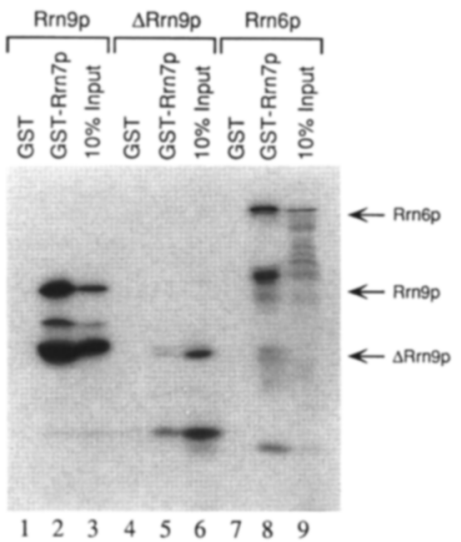

Figure 5. Binding of the $\left[{ }^{35} \mathrm{~S}\right]$ Met-labeled Rrn9p, Rrn6p, and Rrn9p $\Delta 48-197$ to GST-Rrn7p. Equivalent amounts of ${ }^{35}$ S-labeled Rrn9p, Rrn9p $\Delta 48-197$, and Rrn6p were mixed with GST or GST-Rrn7p attached to glutathione-agarose beads for $30 \mathrm{~min}$ at room temperature in a buffer containing $200 \mathrm{mM} \mathrm{KCl}$ and then washed three times with the same buffer. Aliquots of proteins bound to GST (lanes 1, 4, and 7) or GST-Rrn7p beads (lanes 2, 5 , and 81 were analyzed by SDS-PAGE together with ${ }^{35}$ S-labeled proteins that were equivalent to $10 \%$ of the input (lanes 3, 6, and 91. An autoradiogram of the gel is shown. The position of each intact labeled protein probe is indicated by an arrow on the right of the figure.

method to study interactions further among TBP, CFsubunit proteins and UAF-subunit proteins. As shown in Figure 6A, a strong interaction between Rrn9p and TBP was observed (cf. lane 2 with lanes 1 and 9), confirming their physical interaction described in the previous section. Similarly, a significant interaction between TBP and Rrn6p was also observed (Fig. 6A, lane 6 compared with lanes 5 and 91, which is also consistent with the strong physical interaction between the two proteins in vitro. We have also tested interactions between Rrn7p and TBP (Fig. 6A, lanes 7, 8, and 9), as well as Rrn11p and TBP (Fig. 6A, lanes 3, 4, and 9). No positive interactions were detected. Thus, among the three CF-subunit proteins, we have been able to establish a strong interaction with TBP only for Rrn6p both in vitro and in vivo.

As described in the previous section, we detected a significant interaction between $\operatorname{Rrn} 7 p$ and $\operatorname{Rrn} 9 p$ in

Table 2. Binding of ${ }^{35}$ S-labeled Rrn6p, Rrn9p, and Rrn9p 448-197 to GST-Rrn7p and GST

\begin{tabular}{lccc}
\hline & \multicolumn{3}{c}{${ }^{35}$ S probes (\% bound) } \\
\cline { 2 - 4 } & Rrn6p & Rrn9p & $\Delta$ Rrn9p \\
\hline GST & $<1$ & $<1$ & $<1$ \\
GST-Rrn7p & 22 & 45 & 3 \\
\hline
\end{tabular}

The buffer solution used for binding and washing was the same as that described in Table 1 containing $200 \mathrm{~mm} \mathrm{KCl}$. Values given are averages of two experiments, one of which is shown in Fig. 5. 


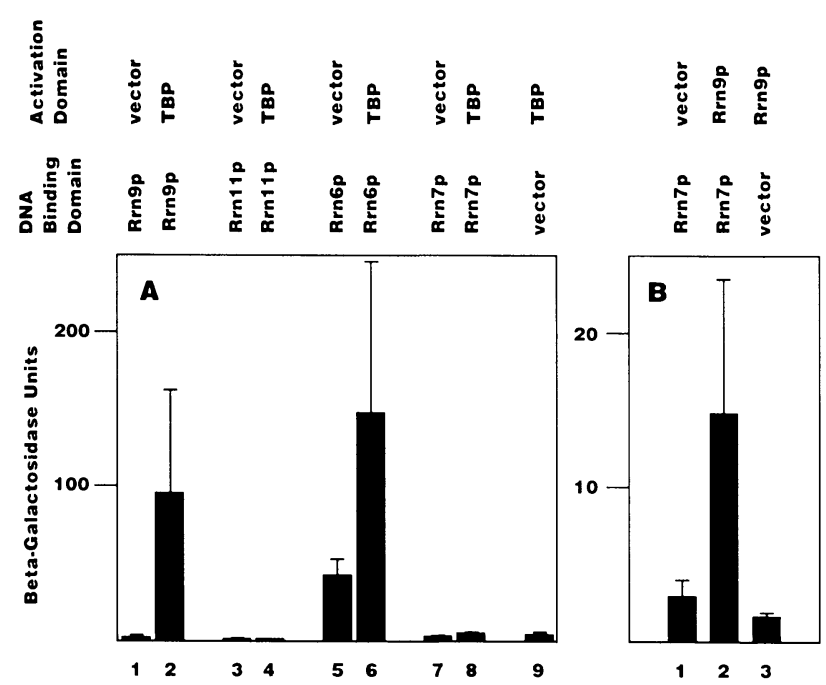

Figure 6. Interactions between TBP, CF-subunit proteins (Rrn6p, Rrn7p, Rrnllp), and a UAF-subunit protein (Rrn9p) analyzed by the two-hybrid system. Protein coding regions were fused to the Gal4p activation domain and/or the Gal4p DNA binding domain. Cells were transformed with plasmids carrying these fusion genes or control vector plasmids in various combinations as indicated above the bar graphs, and $\beta$-galactosidase activities of several independent transformants were analyzed. Average values and standard deviations are shown. We note that the values given in $A$, lanes 2 and 6 , and $B$, lane 2 , are averages of values obtained for 13,8 , and 6 independent transformants, respectively. For each of these groups, individual values varied greatly among transformants resulting in very high standard deviations. We noted that these transformants carrying pairs of plasmids in question grew significantly more slowly than the parental strain, suggesting that the presence of these plasmids is harmful to cell growth. We also noted a tendency of these transformants to lose the plasmids. Thus, we think that the cultures that were analyzed contained cells that had lost plasmids to various extents despite selection of these plasmids by nutritional markers, and that this might account for the observed high variability of $\beta$-galactosidase activity for these transformants in each of these groups. Thus, the average values shown might be lower estimates, and the highest values shown among independent cultures in each of the groups might represent the values closer to the "real" values.

vitro. This interaction, although not as strong as some other combinations mentioned above, was also demonstrated by the two-hybrid system (Fig. 6B, cf. lane 2 with control lanes 1 and 3).

\section{Discussion}

$T B P$ is required for UAF-dependent recruitment of $C F$ to the rDNA promoter

Although the requirement of TBP for rDNA transcription by Pol I has been well established, its functional role in this process has been unknown. The work described in this paper now provides insight into this problem. A model that accounts for the results obtained in our previous as well as the current work (Keys et al. 1994, 1996;
Yamamoto et al. 1996; this paper) is shown in Figure 7 to facilitate discussion.

We have shown previously that UAF interacts with the upstream element of the rDNA promoter, forming a stable UAF-template complex and committing the template to transcription (Keys et al. 1996; Fig. 7B). CF, the essential transcription factor, can then join the complex, but TBP (and perhaps another unidentified factor) is required for recruitment of $\mathrm{CF}$ as demonstrated in the present work (Fig. 7, the step from B to C). Although CF is a component of the resultant stable preinitiation complex (Keys et al. 1994; this work), it has not been demonstrated that TBP (or the other factor) required for CF recruitment actually becomes a part of the complex as envisioned in Figure 7C. Finally, the stable committed

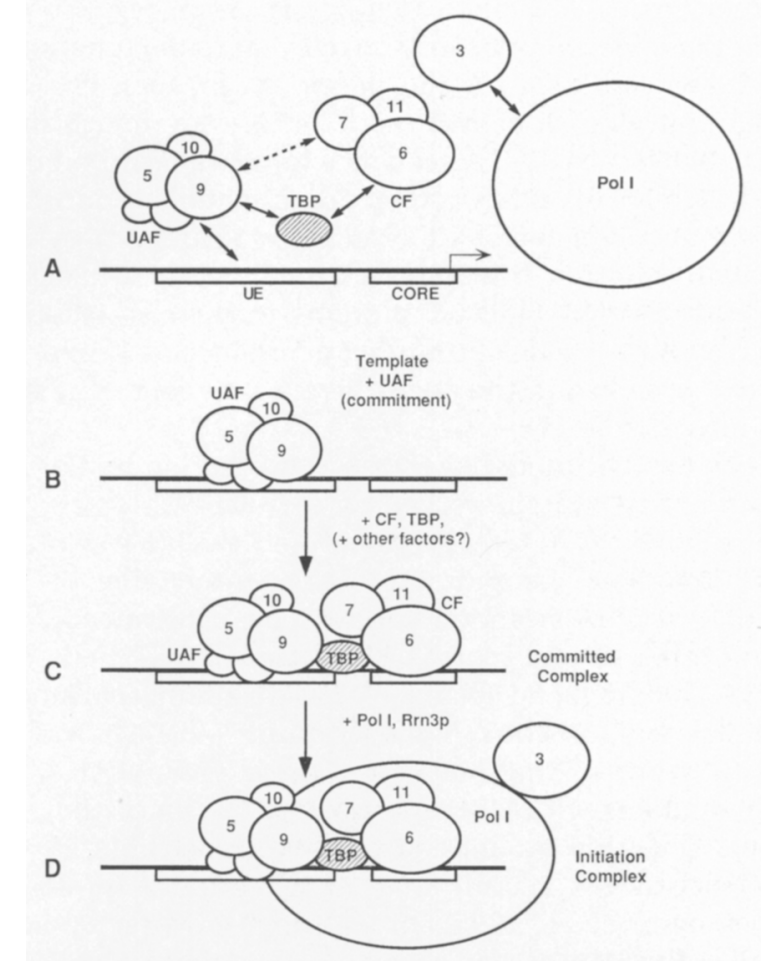

Figure 7. Schematic model of transcription initiation complex assembly at the yeast rDNA promoter. Two elements of the yeast rDNA promoter, the upstream element (UE) and the core element (core), are shown as open boxes. Proteins Rrn3p, Rrn5p, Rrn6p, Rrn7p, Rrn9p, Rrn10p, and Rrnllp are represented by their number designations. The bent arrow indicates the transcription initiation site. Double-headed arrows indicate the observed interactions between UE, UAF, CF, and TBP as well as the interaction between Pol I and Rrn3p (for this interaction, see Yamamoto et al. 1996). The protein-protein interaction observed between Rrn9p and Rrn7p is indicated by a doubleheaded broken line. As noted in the text, some unidentified factor(s) might be required in addition to TBP for recruitment of $\mathrm{CF}$ to the promoter (step $B$ to $C$ ). Note that contacts of proteins with DNA shown in $B, C$, and $D$ are not determined (except for the fact that UAF as a complex binds to DNA) and are for illustration only. The question of whether TBP or Rrn3p is present in the final preinitiation complex $(D)$ is also not known. See the text for details. 
preinitiation complex is able to recruit Pol I, presumably with the aid of the protein encoded by $R R N 3$, and form a Sarkosyl-resistant preinitiation complex that is ready to initiate transcription (Fig. 7D; Yamamoto et al. 1996). Note that both UAF and CF stay with the template during multiple cycles of transcription as a stable complex, but Rrn3p as well as Pol I does not (Yamamoto et al. 1996). In fact, it has not been determined whether Rrn3p is physically present within the final Sarkosyl-resistant preinitiation complex. Demonstration of the requirement of TBP for UAF-dependent recruitment of CF to the rDNA promoter explains why a large stimulation of transcription by TBP was observed for the intact rDNA template containing both the core and the upstream elements and not for the rDNA template without an intact upstream element.

We have shown that both UAF and CF specifically interact with TBP (indicated by arrows in Fig. 7A) and that these interactions may be relevant to the function of TBP to recruit CF to the promoter. In addition, TBP might have direct contact with DNA even though there is no consensus TATA sequence in the rDNA promoter, and such a TBP-DNA interaction might also contribute to the recruitment of CF (see below for further discussion). In addition, direct interaction between some UAFsubunit proteins and CF proteins might also facilitate recruitment of CF; the interaction between Rrn9p and Rrn7p observed in the present work may represent such an interaction (Fig. 7A).

The current model of rDNA transcription by Pol I in mammalian systems proposes that UBF interacts initially with the rDNA promoter and that the resultant UBF-template complex stimulates interaction of SLl with the rDNA promoter, followed by recruitment of Pol I and other factors such as TIF-IA and TIF-IC (Bell et al. 1988; Goodrich and Tjian 1994; for an alternative model, see below and Schnapp and Grummt 1991). It was recently reported that one of the three TAFs $\left(\mathrm{TAF}_{\mathrm{I}} 48\right)$ of SL1 interacts with UBF in vitro, and the suggeistion was made that this interaction may be responsible for the UBF-dependent recruitment of SLl to the promoter (Beckmann et al. 1995). In addition, an interaction of UBF with TBP was also observed (Kwon and Green 1994; Beckmann et al. 1995), and this interaction might also be related to the UBF-dependent recruitment of SL1 (Hempel et al. 1996). Thus there is a superficial resemblance between these experiments and the UAF-dependent and TBP-dependent recruitment of CF in the yeast Pol I system. However, as discussed in detail previously (Keys et al. 1996), there are significant differences between yeast UAF and mammalian UBF. For example, $\mathrm{UBF}$ is a DNA binding protein with low sequence specificity; it interacts not only with the DNA template at a region overlapping the upstream element (UCE in the human rDNA promoter), but also with the DNA template at other regions including a region within the core element. Furthermore, note that the UBF-template interaction is not strong (or specific) enough to commit the template to transcription. Instead, for the mouse rDNA promoter, formation of a stable, committed complex of
TIF-IB (the mouse homolog of SLl) with the promoter was demonstrated in the absence of UBF (Schnapp and Grummt 1991). According to this experimental result, TIF-IB/SL1 resembles UAF rather than CF in the yeast Pol I system. (Because it was not determined in this work whether the observed stable interaction of the DNA template with TIF-IB/SLl took place through the upstream element or the core element of the promoter, significance of the apparent functional correspondence between the mouse TIF-IB/SL1 and the yeast UAF cannot be clearly established.) Thus, exact comparison of mechanisms of recruitment of essential Pol I transcription factors (SLl and $\mathrm{CF}$ ) and a role of TBP in these recruitments between the present yeast system and the mammalian in vitro Pol I system must await future studies.

Comparison of TBP function in the yeast Pol I system with Pol II and Pol III systems

Regarding the role of TBP, there is a certain similarity between the present system and Pol III transcription of tRNA genes in yeast. In the Pol III system, TFIIIC, which is a multiprotein transcription factor like UAF, recognizes box $\mathrm{A}$ and box $\mathrm{B}$ elements and recruits the essential transcription factor TFIIIB, which consists of TBP and two other subunit proteins, the $70-\mathrm{kD}$ Brf protein and the 90-kD B" protein (for review, see Willis 1993; Geiduschek and Kassavetis 1995). Experiments using the three purified TFIIIB subunits showed that Brf alone is able to interact weakly with the DNA-TFIIIC complex presumably through its interaction with the $120-\mathrm{kD}$ subunit of TFIIIC, but the presence of TBP greatly stabilizes this interaction and, in addition, allows binding of the 90-kD B" subunit to the complex, to complete formation of the preinitiation complex that is capable of recruiting Pol III (Kassavetis et al. 1992). Thus, TBP appears to play a role for TFIIIC-dependent recruitment of TFIIIB. Recent work on yeast tRNA gene transcription indicates that a contact of TBP with an AT-rich region of DNA plays a role, in addition to the TFIIIC-TFIIIB interaction, in positioning TFIIIB, further supporting the importance of TBP in TFIIIB recruitment (Joazeiro et al. 1996). It is not known whether TFIIIC, like UAF in the yeast Pol I system, has any direct contact with TBP. In the yeast Pol I system, the Rrn9p subunit of UAF appears to interact not only with TBP, but also with the Rrn7p subunit of $\mathrm{CF}$ (see Fig. 7A). The latter interaction might be analogous to the interaction between the $120-\mathrm{kD}$ subunit of TFIIIC and the Brf subunit of TFIIIB, helping recruitment of CF to the promoter. Also in analogy to the yeast Pol III system, TBP may contact DNA in the rDNA promoter and such a contact might also play a role, in addition to the protein-protein interactions, in the recruitment of $\mathrm{CF}$ to the rDNA promoter. In fact, there is an extended AT-rich region (from -93 to $-60 ; 80 \%$ AT) upstream of the core element in addition to several other sequences in which TBP might have some affinity. Mutational analyses should give an answer to the question of TBP- 
DNA contact and its possible significance in the recruitment of CF by TBP.

The function of TBP demonstrated in the present yeast Pol I system also has a certain similarity to the function of TBP in initiator-containing and TATA-less Pol II promoters. It has been demonstrated that TAFs (in association with TBP) in the human TFIID complex are essential for both activator-dependent and activator-independent ("basal") transcription of a TATA-less promoter that carries an essential initiator element (Martinez et al. 1994). Direct interaction of the $\mathrm{TAF}_{\mathrm{II}} 150$ subunit of Drosophila TFIID with DNA around the transcription start site also was shown (Verrijzer et al. 1994, 1995). For such Pol II promoters, at least in the absence of activators, it appears that the initial important interaction may be the interaction of certain TAFs with DNA elements such as initiator elements [and downstream promoter elements (DPE) identified recently by Burke and Kadonaga 1996], rather than the interaction of TBP with DNA. In these instances, the role of TBP in TFIID is to recruit TFIIB, the essential transcription factor required for Pol II recruitment, presumably through its direct contact with TFIIB (Nikolov et al. 1995) as discussed by previous investigators (Martinez et al. 1994, 1995; Verrijzer et al. 1994, 1995; Joazeiro et al. 1996). Thus, in these initiator(and DPE-) dependent and TATA-less Pol II promoter systems, it appears that the TAF-initiator (and DPE) interaction may be analogous to the UAF-upstream-element interaction and that TFIIB recruitment by TBP may be analogous to CF recruitment by TBP in the yeast Pol I system.

Discovery of transcription factors complexed with TBP for transcription by all three eukaryotic nuclear RNA polymerases, Pol I, Pol II, and Pol III, has led to the concept that the majority of TBP in cells is complexed with other specific proteins, called TAFs, and that these TBP-TAF complexes represent functional units, participating in promoter selection and transmitting regulatory signals to the polymerases (e.g., see Goodrich and Tjian 1994). Many experiments were carried out to support this concept. However, this does not necessarily mean that the TBP-TAF complexes found in Pol I, Pol II, and Pol III systems (i.e., SL1 in Pol I, TFIID in Pol II, and TFIIIB in Pol III systems) carry out analogous functions. As already discussed above, the main function of TFIIIB is to recruit Pol III, which makes TFIIIB analogous to TFIIB rather than the TBP-containing TFIID in Pol II systems. For the yeast Pol I transcription system, TBP exists apparently "free" in extracts [which were prepared in the presence of $400 \mathrm{~mm}\left(\mathrm{NH}_{4}\right)_{2} \mathrm{SO}_{4}$ in our studies], but may be associated loosely with both UAF and CF as judged from the results presented in this paper. As discussed above, TBP-UAF appears to resemble the TBPcontaining complex TFIID (in TATA-less promoter systems), and TBP-CF appears to resemble the TBP-containing complex TFIIIB. The essential function of TBP may be to interact with a specific region of DNA and/or other specific DNA-binding transcription factor(s) and to mediate recruitment of still another essential transcription factor that is crucial for recruitment of RNA poly- merases to correct start sites on the template. Depending on polymerase systems and on experimental cell systems, some particular interactions may be stronger than others, leading to isolation of different kinds of TBPcontaining complexes. Mammalian SLl might in fact correspond to the TBP-CF complex in the yeast Pol I system, but it is not clear whether the basis of its function in correctly positioning Pol I on the promoter is the same as that used in the yeast Pol I system. In addition, the possibility also exists that SL1/TIF-IB might actually correspond to the TBP-UAF complex in the yeast system in view of the template commitment experiments published by Schnapp and Grummt (1991). Thus, establishing functional correspondence between mammalian SL1 and yeast CF or UAF (plus TBP) will need further experimental studies.

\section{Materials and methods}

Strains and plasmids

The strains and plasmids used in this study are listed in Table 3. Plasmids used to study protein-protein interactions by the yeast two-hybrid system were prepared as derivatives of pASI$\mathrm{CYH} 2$ or pACTII. For construction of pNOY355, a $5^{\prime} \mathrm{NcOI}$ site and a $3^{\prime} B a m H I$ site were added to the $1.1-\mathrm{kb} R R N 9$ coding region by PCR. The PCR product was digested with NcoI and $B a m H I$ and the fragment obtained was ligated into the multicloning site of pASI-CYH2 between the NcoI and BamHI sites, fusing RRN9 to GAL4 (1-147) in frame. This fusion changed the second amino acid of Rrn9p from serine to glycine. For construction of pNOY356, a 5' NcoI site was added to the RRN11 coding region (from pNOY349; Lalo et al. 1996) by PCR and the resulting $1.7-\mathrm{kb}$ NcoI-SmaI fragment encoding Rrn 1 lp was ligated between the $\mathrm{NcOI}$ and $\mathrm{BamHI}$ sites of pASI-CYH2, changing the second amino acid of Rrnllp from phenylalanine to valine. For construction of pNOY357, the $3.1-\mathrm{kb}$ NdeI-HindIII fragment from pNOY214 (Keys et al. 1994) encoding the HAltagged Rrn6p was ligated between the NdeI and BamHI sites of pASI-CYH2. For construction of pNOY358, the 1.6-kb coding region of the $R R N 7$ gene was created by PCR and ligated into the blunted NdeI site of pASI-CYH2. This fusion started at the second amino acid of Rrn7p, which was changed from serine to threonine.

For the construction of pNOY359, the BamHI fragment from pNOY3248 encoding yeast TBP was ligated into the $X$ hol site of pACTII. For the construction of pNOY360, a $5^{\prime} \mathrm{NcoI}$ site and a $3^{\prime} B a m H I$ site were added to the 1.1-kb RRN9 coding region by PCR. This PCR fragment was ligated between the NcoI and BamHI sites of pACTII. This fusion changed the second amino acid of Rrn9p from serine to glycine. All plasmids constructed for the two-hybrid system experiments, as described above, were transformed into yeast strain SFY526 and checked for expression of fusion proteins by Western immunoblot analysis, making use of the $\mathrm{HAl}$ epitope programmed into the fusions in pACTII and pASI-CYH2.

Plasmid pNOY3246, which was used to make ${ }^{35} \mathrm{~S}$-labeled Rrn9p, was constructed by inserting the $1.1-\mathrm{kb}$ NcoI-BamHI coding region of $R R N 9$ from pNOY355 (which has a change from serine to glycine at the second amino acid; see above) between HincII and BamHI sites of pBS(-). Plasmid pNOY3247 was a derivative pNOY3246 and was constructed by deleting DNA between the XbaI site and the XmnI site within the RRN9 coding region. 
Table 3. Yeast strains and plasmids

\begin{tabular}{|c|c|}
\hline Designation & Description \\
\hline \multicolumn{2}{|l|}{ Yeast strains } \\
\hline JHRY20-2CA1 (NOY203) & 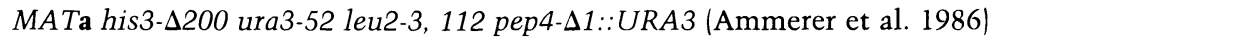 \\
\hline SHY70 & 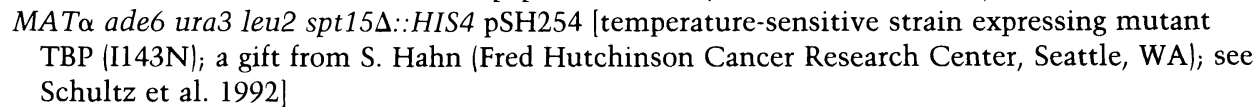 \\
\hline SFY526 & $\begin{array}{l}\text { MATa ura3-52 his3-200 ade2-101 lys2-801 trpl-901 leu2-3, } 112 \operatorname{can}^{\mathrm{r}} \text { gal4-542, gal80-538 } \\
\text { URA3::GAL1-lacZ (Clontech, Palo Alto, CA) }\end{array}$ \\
\hline NOY567 & MAT $\alpha$ ade2-1 ura3-1 leu2-3, 112 trp1-1 his3-1 can1-100 rrn6A::LEU2 pNOY103 \\
\hline NOY662 & MAT $\alpha$ ade2 ade3 leu2 ura3 trp1 his can1 rrn5::TRP1 pNOY330 \\
\hline NOY696 & MAT $\alpha$ ade2 ade3 leu2 ura3 lys2 his can1 rrn10-1 pNOY103 \\
\hline NOY732 & MATa ade2-1 ura3-1 leu2-3, 112 trp1-1 his3-11 can1-100 rrn7A::LEU2 pNOY303 \\
\hline \multicolumn{2}{|l|}{ Plasmids } \\
\hline pACTII & $\begin{array}{l}\text { A derivative of pACT (Durfee et al. 1993); LEU2, } 2 \mu, a m p^{r} \text { and carries the GAL4 transcription } \\
\text { activation domain [GAL4 }(768-881)] \text {, which is under the } A D H \text { promoter and is followed by } \\
\text { the region encoding a HA1-flu epitope tag and multicloning sites (a gift from S.J. Elledge, } \\
\text { Baylor College of Medicine, Houston, TX) }\end{array}$ \\
\hline pASI-CYH2 & $\begin{array}{l}\text { A derivative of pASI (Durfee et al. 1993); TRP1,CYH2, } 2 \mu, a m p^{r} \text { and carries the GAL4 DNA } \\
\text { binding domain [GAL4(1-147)], which is under the } A D H \text { promoter and is followed by the } \\
\text { region encoding a HAl-flu epitope tag and multicloning sites (a gift from S.J. Elledge) }\end{array}$ \\
\hline 6-HisTyIID & $\begin{array}{l}\text { A derivative of } 6 \text { HisT-pET11 expression vector carrying SPT15 for yeast TBP (a gift from R.G. } \\
\text { Roeder, Rockefeller University, New York, NY; see Hoffmann and Roeder 1991) }\end{array}$ \\
\hline pSH254 & $\begin{array}{l}\text { ARS CEN LEU2 vector carrying spt15 (encoding the mutant TBP I143N; Schultz et al. 1992; a } \\
\text { gift from S. Hahn) }\end{array}$ \\
\hline pNOY103 & High-copy-number plasmid carrying GAL7-35S rDNA, $A D E 32 \mu a m p^{T}$ (Nogi et al. 1991) \\
\hline pNOY221 & A derivative of pRS316 carrying HAl-tagged RRN7 (Lalo et al. 1996) \\
\hline pNOY303 & $\begin{array}{l}\text { A derivative of pRS314 (CEN6 ARS4 URA3) carrying a DNA fragment encoding triple } \\
\text { HA1-tagged Rrn7p (Lalo et al. 1996) }\end{array}$ \\
\hline pNOY330 & $\begin{array}{l}\text { A derivative of pPC97 (LEU2 CEN6 amp }{ }^{r} \text { ) carrying a DNA fragment encoding triple } \\
\text { HAl-tagged Rrn5p (Keys et al. 1996) }\end{array}$ \\
\hline pNOY355 & A derivative of pASI-CYH2 carrying GAL4(1-147)-RRN9 fusion gene \\
\hline pNOY356 & A derivative of $\mathrm{pASI}-\mathrm{CYH} 2$ carrying $G A L 4(1-147)-R R N 11$ fusion gene \\
\hline pNOY357 & A derivative of pASI-CYH2 carrying $G A L 4(1-147-R R N 6$ fusion gene \\
\hline pNOY358 & A derivative of pASI-CYH2 carrying $G A L 4(1-147)-R R N 7$ fusion gene \\
\hline pNOY359 & A derivative of pACTII carrying GAL4(768-881)-SPT15 fusion gene (SPT15 encodes TBP) \\
\hline pNOY360 & A derivative of pACTII carrying GAL4(768-881)-RRN9 fusion gene \\
\hline pNOY3173 & A derivative of $\mathrm{pBS}(-)$ carrying $R R N 6$ fused to the CITE sequence (Lalo et al. 1996) \\
\hline pNOY3244 & $\begin{array}{l}\text { A derivative of pGEX-3X (Pharmacia) carrying } R R N 7 \text { fused to the GST coding region (Lalo et al. } \\
\text { 1996) }\end{array}$ \\
\hline pNOY3245 & A derivative of $\mathrm{pBS}(-)$ carrying $R R N 11$ fused to the CITE sequence (Lalo et al. 1996) \\
\hline pNOY3246 & A derivative of $\mathrm{pBS}(-)$ carrying $R R N 9$ \\
\hline pNOY3247 & A derivative of pNOY3246 carrying the mutant $r r n 9$ gene encoding Rrn9p $\Delta 48-197$ \\
\hline pNOY3248 & $\begin{array}{l}\text { A derivative of pGEX-1 carrying SPT15 (the gene for TBP) fused to the GST coding region (a gift } \\
\text { from J.C. Reese, University of Massachusetts Medical Center, Worchester, MA; see Reese et } \\
\text { al. 1994). }\end{array}$ \\
\hline
\end{tabular}

\section{$U A F, C F$, and TBP preparations}

The UAF complex preparation used in GST-TBP binding and in template competition experiments was purified from a strain (NOY662) expressing triple-HA1-tagged Rrn5p by affinity chromatography using immobilized 12CA5 (anti-HAl) monoclonal antibody, followed by heparin-Sepharose and Mono S chromatography as described previously (Keys et al. 1996). The CF complex preparation used in GST-TBP binding experiments was similarly purified from a strain (NOY732) expressing tripleHAl-tagged Rrn7p by affinity chromatography using immobilized 12CA5 monoclonal antibody followed by heparin-Sepharose chromatography as previously described (Keys et al. 1994). Partially purified CF complex (H-400 fraction) used in template competition experiments was prepared from a wild-type yeast strain (NOY203) by phosphocellulose, DEAE cellulose, and hep- arin agarose chromatography as previously described (Keys et al. 1994). His-tagged yeast TBP was expressed in Escherichia coli carrying plasmid 6-HisTyIID, and then purified by $\mathrm{Ni}^{2+}$-affinity chromatography as described by Hoffmann and Roeder (1991).

\section{In vitro transcription reactions}

Transcription extracts (D-300 plus PC-300 fractions) were prepared as previously described (Keys et al. 1994) from rrn6 deletion-mutant strain NOY567, rrn10-1 mutant strain NOY696, and temperature-sensitive spt15 (TBP) mutant strain SHY70. In vitro transcription reactions were performed as described previously (Keys et al. 1994). Typical in vitro reactions contained, in the 40- $\mu$ l reaction volume: $3-6 \mu$ l of D-300 fraction $(\sim 20 \mu \mathrm{g}$ of protein) plus 5-9 $\mu$ l of PC-300 fraction ( $\sim 2-4 \mu \mathrm{g}$ of protein) and $200 \mathrm{ng}(5 \mu \mathrm{g} / \mathrm{ml})$ of circular supercoiled DNA template in ad- 
dition to other standard components. The DNA template used for most assays is pSIRT containing a yeast rDNA minigene that generates a specific transcript of $\sim 765$ nucleotides (Keys et al. 1994; for the structure of pSIRT, see Musters et al. 1989). The mutant rDNA template used in the experiments shown in Figure 2 is pSIRT $\Delta-208 /-91$, containing a $5^{\prime}$ deletion from -208 to -91 (with respect to the transcription start site) that removes part of the upstream promoter element of the rDNA promoter (Musters et al. 1989; Kulkens et al. 1991). Template B used in template competition experiments (Fig. 3 ) is the $3^{\prime}$-deletion construct pSIRT $\Delta+39 /+128$, which contains a wild-type rDNA promoter and generates a specific transcript of $\sim 690 \mathrm{nu}-$ cleotides ( 75 nucleotides shorter than that generated by pSIRT; Kulkens et al. 1991). In the experiments shown in Figure 1, A and $\mathrm{B}$, the transcription extracts and glutathione-eluted samples were allowed to preincubate with the DNA template for $2 \mathrm{hr}$ at room temperature prior to the addition of nucleoside triphosphates. For the template competition experiment shown in Figure 3 , the two DNA templates (400 ng each) were separately preincubated with the indicated protein fractions for $2 \mathrm{hr}$ at room temperature to allow the formation of stable complexes on the DNA template. The two protein/template mixtures were then combined and incubated an additional $30 \mathrm{~min}$ to allow unbound factors to equilibrate between the two DNA templates, and then nucleoside triphosphates were added to allow transcription to begin. Transcription reactions were carried out for $40 \mathrm{~min}$ at room temperature, and radioactive RNA synthesized was analyzed by $5 \%$ urea-PAGE followed by autoradiography.

Protein-protein and protein-factor interactions using glutathione-agarose beads with bound GST fusion proteins

GST-Rrn7p and GST-TBP fusion proteins were prepared by induction of E. coli strains carrying pNOY3244 and pNOY3248, respectively, with IPTG followed by affinity purification of fusion proteins from extracts using glutathione-agarose beads (Sigma). Protein concentrations on the beads were analyzed by Bradford analysis and then adjusted to $5 \mathrm{mg} / \mathrm{ml}$ in a $50 \%$ slurry.

$\left[{ }^{35}\right.$ S]Met-labeled Rrn6p, HAl-Rrn7p, Rrnllp, Rrn9p, and Rrn9p $\Delta 48-197$ were synthesized in vitro using rabbit reticulocyte systems (Promega) with pNOY3173, pNOY221, pNOY3245, pNOY3246, and pNOY3247 as respective templates. The labeled proteins were added in approximately equal molar amounts (see legend to Fig. 4) to GST-Rrn7p, GST-TBP, or GST control, bound to glutathione-agarose beads $(10 \mu)$, as described above) that had been pre-equilibrated with Buffer $\mathrm{B}(20$ $\mathrm{mm}$ Tris-acetate at $\mathrm{pH} 8.0,10 \mathrm{~mm} \mathrm{Mg}$ acetate, $30 \%$ glycerol, $0.2 \%$ BSA, $0.5 \%$ Tween-20, $1 \mathrm{~mm}$ PMSF, and $10 \mu \mathrm{g} / \mathrm{ml}$ of the following protease inhibitors: aprotinin, chymostatin, leupeptin, antipain, bestatin, and pepstatin) containing various concentrations of salts in a final volume of $200 \mu \mathrm{l}$. After $30 \mathrm{~min}$ at room temperature with gentle agitation, the beads were recovered and washed three times with $1 \mathrm{ml}$ of incubation buffer. The bound proteins were analyzed by SDS-PAGE followed by autoradiography and were quantified by cutting out pertinent protein bands and determining radioactivity using a liquid scintillation counter.

For binding of native UAF or CF complexes to GST-TBP, affinity-purified UAF or affinity-purified CF complexes (see above) were incubated with $10 \mu$ l of GST-TBP bound to glutathione-agarose beads in a total volume of $200 \mu \mathrm{l}$ of Buffer B containing $200 \mathrm{~mm} \mathrm{KCl}, 400 \mathrm{~mm} \mathrm{KCl}$, or $400 \mathrm{~mm} \mathrm{~K}$ glutamate, as indicated. For controls, an equal amount of UAF or CF complex was incubated with an equivalent amount of GST alone bound to glutathione-agarose beads or of glutathione-agarose beads alone. After $30 \mathrm{~min}$ incubation at room temperature, the beads were gently pelleted, the supernatant was removed, and the beads were washed three times with $1 \mathrm{ml}$ of the incubation buffer. Bound complexes were then eluted with $40 \mu \mathrm{l}$ of $15 \mathrm{~mm}$ glutathione in the binding buffer, and $25 \mu \mathrm{l}$ was analyzed by Western immunoblot using monoclonal antibody specific for the HAl epitope. For in vitro transcription reactions, the bound complexes were eluted twice in a minimal volume $(10 \mu \mathrm{l})$ of 30 mM glutathione in binding buffer, and $4 \mu \mathrm{l}$ of the second eluate, which contained most of the eluted complexes, was used for the assay.

Analysis of protein-protein interactions by yeast two-hybrid system

Plasmid pASI-CYH2 carrying the gene for Gal4p DNA binding domain (1-147) and pACTII carrying the gene for Gal4p transcription activation domain (768-881) were obtained from S. Elledge and were used as control vectors. Various genes fused to the Gal4p DNA binding domain or the Gal4p activation domain were constructed using these two plasmids and then introduced into yeast strain SFY526 as pairs to study protein-protein interactions as originally described by Fields and Song (1989). Transformants carrying plasmid pairs were selected on glucose synthetic media lacking leucine and tryptophan. From 5 to 13 individual transformants were picked and grown in $20 \mathrm{ml}$ of glucose selective media to an $\mathrm{OD}_{600} \leqslant 1.0$. Cells were collected and stored at $-70^{\circ} \mathrm{C}$. Cells were then broken on ice with glass beads in Buffer $\mathrm{Z}$ (100 mM Na phosphate, $\mathrm{pH} 7.0,10 \mathrm{mM} \mathrm{KCl}, 1$ $\mathrm{mM} \mathrm{MgSO} 4,10 \%$ glycerol and $38 \mathrm{~mm} \beta$-mercaptoethanol) containing $1 \mathrm{mM}$ PMSF. The lysate was centrifuged and protein concentrations of the supernatant were determined by Bradford analysis. From 5 to $30 \mu$ l of supernatant was used to assay $\beta$-galactosidase activity (Miller 1972), and the enzyme activity was expressed in units that were calculated as nanomoles of ONPG hydrolyzed per minute per milligram of protein, using the conversion factor $0.0045 \mathrm{~A}_{420}=1$ nmole ONPG hydrolyzed. A control positive pair of plasmids from Clontech, pVA3 (carrying murine $\mathrm{p} 53$ fused to the Gal4p DNA binding domain) and pTD1 (carrying SV40 large T-antigen fused to Gal4p activation domain), gave $\beta$-galactosidase units measuring $59 \pm 11$ units.

\section{Acknowledgments}

We thank Dr. Joseph Reese for the plasmid pNOY3248 and for his helpful suggestions concerning expression and use of GST-TBP, Dr. Steven Hahn for the yeast strain SHY70, Dr. Robert Roeder for the plasmid 6-HisTyIID, Dr. S.J. Elledge for the plasmids pASI-CYH2 and pACTII, and Laura Burson and Dr. John Keener for preparation of His-tagged TBP. We thank Drs. Karyl Minard, Robert Haselbeck, and Dominique Lalo for suggestions concerning the yeast two-hybrid system. We also thank Drs. John Keener, Marian Waterman, and Suzanne Sandmeyer for critical reading of the manuscript, and Diane Semanko for its preparation. This work was supported by U.S. Public Health Grant R37GM35949 from the National Institutes of Health.

The publication costs of this article were defrayed in part by payment of page charges. This article must therefore be hereby marked "advertisement" in accordance with 18 USC section 1734 solely to indicate this fact. 


\section{References}

Ammerer, G., C.P. Hunter, J.H. Rothman, G.C. Saari, L.A. Valls, and T.H. Stevens. 1986. PEP4 gene of Saccharomyces cerevisiae encodes proteinase $\mathrm{A}$, a vacuolar enzyme required for processing of vacuolar precursors. Mol. Cell. Biol. 6: 24902499.

Beckmann, H., J.-L. Chen, T. O'Brien, and R. Tjian. 1995. Coactivator and promoter-selective properties of RNA polymerase I TAFs. Science 270: 1506-1509.

Bell, S.P., R.M. Learned, H.-M. Jantzen, and R. Tiian. 1988. Functional cooperativity between transcription factors UBF1 and SLl mediates human ribosomal RNA synthesis. Science 241: 1192-1197.

Buratowski, S. 1994. The basics of basal transcription by RNA polymerase II. Cell 77: 1-3.

Burke, T.W. and J.T. Kadonaga. 1996. Drosophila TFIID binds to a conserved downstream basal promoter element that is present in many TATA-box-deficient promoters. Genes \& Dev. 10: 711-724.

Choe, S.Y., M.C. Schultz, and R.H. Reeder. 1992. In vitro definition of the yeast RNA polymerase I promoter. Nucleic Acids Res. 20: 279-285.

Comai, L., N. Tanese, and R. Tiian. 1992. The TATA-binding protein and associated factors are integral components of the RNA polymerase I transcription factor, SL1. Cell 68: 965976.

Comai, L., J.C.B.M. Zomerdijk, H. Beckmann, S. Zhou, A. Admon, and R. Tjian. 1994. Reconstitution of transcription factor SL1: Exclusive binding of TBP by SL1 or TFIID subunits. Science 266: 1966-1972.

Conaway, R.C. and J.W. Conaway. 1993. General initiation factors for RNA polymerase II. Annu. Rev. Biochem. 62: 161190.

Cormack, B.P. and K. Struhl. 1992. The TATA-binding protein is required for transcription by all three nuclear RNA polymerases in yeast cells. Cell 69: 685-696.

Durfee, T., K. Becherer, P.-L. Chen, S.-H. Yeh, Y. Yang, A.E. Kilburn, W.-H. Lee, and S.J. Elledge. 1993. The retinoblastoma protein associates with the protein phosphatase type 1 catalytic subunit. Genes \& Dev. 7: 555-569.

Eberhard, D., L. Tora, J.-M. Egly, and I. Grummt. 1993. A TBPcontaining multiprotein complex (TIF-IB) mediates transcription specificity of murine RNA polymerase I. Nucleic Acids Res. 21: 4180-4186.

Fields, S. and O. Song. 1989. A novel genetic system to detect protein-protein interactions. Nature 340: 245-246.

Fields, S. and R. Sternglanz. 1994. The two-hybrid system: An assay for protein-protein interactions. Trends Genet. 10: $286-292$.

Geiduschek, E.P. and G.A. Kassavetis. 1995. Comparing transcriptional initiation by RNA polymerases I and III. Curr. Opin. Cell Biol. 7: 344-351.

Goodrich, J.A. and R. Tjian. 1994. TBP-TAF complexes: selectivity factors for eukaryotic transcription. Curr. Opin. Cell Biol. 6: 403-409.

Hempel, W.H., A.H. Cavanaugh, R.D. Hannan, L. Taylor, and L.T. Rothblum. 1996. The species-specific RNA polymerase I transcription factor SL-1 binds to upstream binding factor. Mol. Cell. Biol. 16: 557-563.

Hernandez, N. 1993. TBP, a universal eukaryotic transcription factor? Genes \& Dev. 7: 1291-1308.

Hoffmann, A. and R.G. Roeder. 1991. Purification of his-tagged proteins in non-denaturing conditions suggests a convenient method for protein interaction studies. Nucleic Acids Res. 19: 6337-6338.
Joazeiro, C.A., G.A. Kassavetis, and E.P. Geiduschek. 1996. Alternative outcomes in assembly of promoter complexes: The roles of TBP and a flexible linker in placing TFIIIB on tRNA genes. Genes \& Dev. 10: 725-739.

Kassavetis, G.A., C.A. Joazeiro, M. Pisano, E.P. Geiduschek, T. Colbert, S. Hahn, and J.A. Blanco. 1992. The role of the TATA-binding protein in the assembly and function of the multisubunit yeast RNA polymerase III transcription factor, TFIIIB. Cell 71: 1055-1064.

Keys, D.A., L. Vu, J.S. Steffan, J.A. Dodd, R.T. Yamamoto, Y. Nogi, and M. Nomura. 1994. RRN6 and RRN7 encode subunits of a multiprotein complex essential for the initiation of rDNA transcription by RNA polymerase I in Saccharomyces cerevisiae. Genes \& Dev. 8: 2349-2362.

Keys, D.A., B.-S. Lee, J.A. Dodd, T.T. Nguyen, L. Vu, E. Fantino, L.M. Burson, Y. Nogi, and M. Nomura. 1996. Multiprotein transcription factor UAF interacts with the upstream element of the yeast RNA polymerase I promoter and forms a stable preinitiation complex. Genes \& Dev. 10: 887-903.

Kulkens, T., D.L. Riggs, J.D. Heck, R.J. Planta, and M. Nomura. 1991. The yeast RNA polymerase I promoter: Ribcisomal DNA sequences involved in transcription initiaticn and complex formation in vitro. Nucleic Acids Res. 19: 53635370 .

Kwon, H. and M.R. Green. 1994. The RNA polymerase I transcription factor, upstream binding factor, interacts directly with the TATA box-binding protein. I. Biol. Chem. 269: 30140-30146.

Lalo, D., J.S. Steffan, J.A. Dodd, and M. Nomura. 1996. RRN11 encodes the third subunit of the complex containing Rrn6p and Rrn $7 p$ that is essential for the initiation of rDNA transcription by yeast RNA polymerase I. J. Biol. Chem. 271: 21062-21067.

Lin, C.H., B. Moorefield, J. Payne, P. Aprikian, K. Mitomo, and R.H. Reeder. 1996. A novel 66-kilodalton protein complexes with Rrn6p, Rrn7p, and TATA-binding protein to promote polymerase I transcription initiation in Saccharomyces cerevisiae. Mol. Cell. Biol. 16: (in press.)

Martinez, E., C.-M. Chiang, H. Ge, and R.G. Roeder. 1994. TATA-binding protein-associated factor(s) in TFIID function through the initiator to direct basal transcription from a TATA-less class II promoter. EMBO I. 13: 3115-3126.

Martinez, E., Q. Zhou, N.D. L'Etoile, T. Oelgeschlager, A.J. Berk, and R.G. Roeder. 1995. Core promoter-specific function of a mutant transcription factor TFIID defective in TATA-box binding. Proc. Natl. Acad. Sci. 92: 11864-11868.

Miller, J.H. 1972. Unit VII: Assays of the lac operon enzymes, experiment 48: Assay of $\beta$-galactose. In Experiments in molecular-genetics, pp. 352-355. Cold Spring Harbor Laboratory, Cold Spring Harbor, NY.

Moss, T. and V.Y. Stefanovsky. 1995. Promotion and regulation of ribosomal transcription in eukaryotes by RNA polymerase I. Prog. Nucleic Acids Res. Mol. Biol. 50: 25-66.

Musters, W., J. Knol, P. Maas, A.F. Dekker, H. van Heerikhuizen, and R.J. Planta. 1989. Linker scanning of the yeast RNA polymerase I promoter. Nucleic Acids Res. 17: 9661-9678.

Nikolov, D.B., H. Chen, E.D. Halay, A.A. Usheva, K. Hisatake, D.K. Lee, R.G. Roeder, and S.K. Burley. 1995. Crystal structure of a TFIIB-TBP-TATA-element ternary complex. $\mathrm{Na}$ ture 377: 119-128.

Nogi, Y., L. Vu, and M. Nomura. 1991. An approach for isolation of mutants defective in $35 \mathrm{~S}$ ribosomal RNA synthesis in Saccharomyces cerevisiae. Proc. Natl. Acad. Sci. 88: 70267030.

Paule, M.R. 1994. Transcription of ribosomal RNA by eukaryotic RNA polymerase I. In Transcription: Mechanisms and 
regulation (ed. R.C. Conaway and J.W. Conaway), pp. 83106. Raven Press, New York, NY.

Phizicky, E.M. and S. Fields. 1995. Protein-protein interactions: Methods for detection and analysis. Microbiol. Rev. 59: 94 123.

Reeder, R.H. 1992. Regulation of transcription by RNA polymerase I. In Transcription regulation (ed. S.L. McKnight and K.R. Yamamoto), Vol. 2, pp. 315-348. Cold Spring Harbor Laboratory Press, Cold Spring Harbor, NY.

Reese, J.C., L. Apone, S.S. Walker, L.A. Griffin, and M.R. Green. 1994. Yeast $\mathrm{TAF}_{\mathrm{II}} \mathrm{S}$ in a multisubunit complex required for activated transcription. Nature 371: 523-527.

Schnapp, A. and I. Grummt. 1991. Transcription complex formation at the mouse rDNA promoter involves the stepwise association of four transcription factors and RNA polymerase I. J. Biol. Chem. 266: 24,588-24,595.

Schultz, M.C., R.H. Reeder, and S. Hahn. 1992. Variants of the TATA-binding protein can distinguish subsets of RNA polymerase I, II, and III promoters. Cell 69: 697-702.

Struhl, K. 1994. Duality of TBP, the universal transcription factor. Science 263: 1103-1104.

Verrijzer, C.P., K. Yokomori, J.-L. Chen, and R. Tjian. 1994. Drosophila TAF $_{\mathrm{II}}$ 150: Similarity to yeast gene TSM-1 and specific binding to core promoter DNA. Science 264: 933941.

Verrijzer, C.P., J.-L. Chen, K. Yokomori, and R. Tjian. 1995. Binding of TAFs to core elements directs promoter selectivity by RNA polymerase II. Cell 81: 1115-1125.

Willis, I.M. 1993. RNA polymerase III. Genes, factors and transcriptional specificity. Eur. I. Biochem. 212: 1-11.

Yamamoto, R.T., Y. Nogi, J.A. Dodd, and M. Nomura. 1996. $R R N 3$ gene of Saccharomyces cerevisiae encodes an essential RNA polymerase I transcription factor which interacts with the polymerase independently of DNA template. EMBO I. 15: 3964-3973.

Zawel, L. and D. Reinberg. 1995. Common themes in assembly and function of eukaryotic transcription complexes. Annu. Rev. Biochem. 64: 533-561.

Zomerdijk, J.C.B.M., H. Beckmann, L. Comai, and R. Tjian. 1994. Assembly of transcriptionally active RNA polymerase I initiation factor SLl from recombinant subunits. Science 266: 2015-2018. 


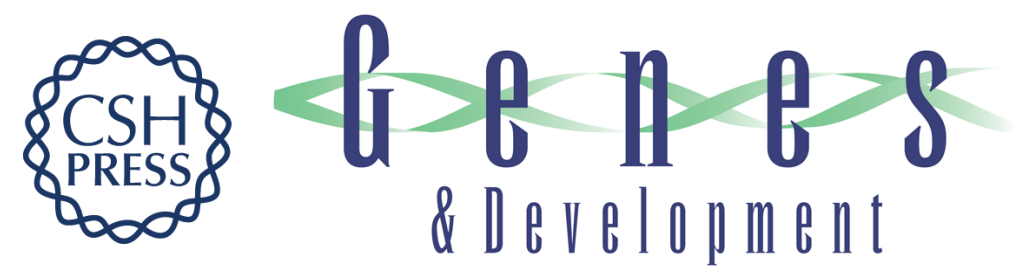

\section{The role of TBP in rDNA transcription by RNA polymerase I in Saccharomyces cerevisiae: TBP is required for upstream activation factor-dependent recruitment of core factor.}

J S Steffan, D A Keys, J A Dodd, et al.

Genes Dev. 1996, 10:

Access the most recent version at doi:10.1101/gad.10.20.2551

References This article cites 43 articles, 19 of which can be accessed free at:

http://genesdev.cshlp.org/content/10/20/2551.full.html\#ref-list-1

License

Email Alerting Receive free email alerts when new articles cite this article - sign up in the box at the top Service right corner of the article or click here.

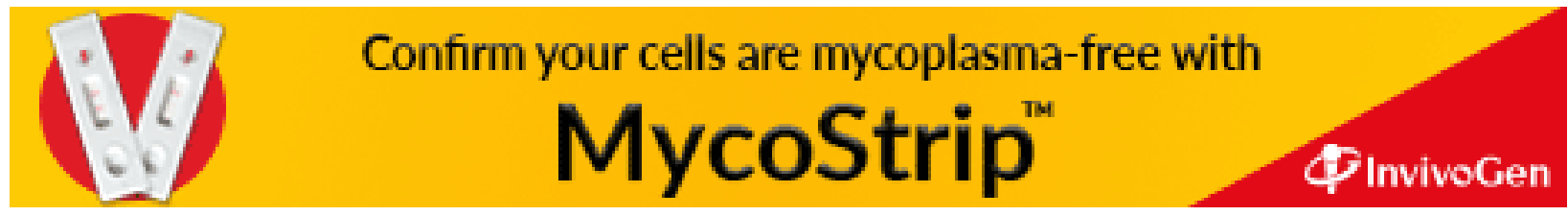

